\title{
Profundidade de semeadura e superação de dormência no crescimento inicial de sementes de Brachiaria dictyoneura (Fig. \& De Not.) Stapf (1919) cv. Llanero
}

\author{
Alan Mario Zuffo ${ }^{1}$, Fabrício Ribeiro Andrade 2 , Luana Maria Alves da Silva ${ }^{3}$, Karen Oliveira de Menezes, \\ Roberto Lustosa da Silva ${ }^{5}$ Adelfran Cavalcante Piauilino ${ }^{6}$
}

http://dx.doi.org/10.1590/0034-737X20146106009

\begin{abstract}
RESUMO
O Brasil é o maior produtor, consumidor e exportador de sementes de espécies forrageiras de clima tropical. Objetivou-se, com este estudo, avaliar o desenvolvimento inicial de Brachiaria dictyoneura cv. Llanero, em função da profundidade de semeadura e dos métodos de superação de dormência. $\mathrm{O}$ trabalho foi realizado em casa de vegetação, em blocos casualizados, com quatro repetições e em esquema de parcela subdividida. Os tratamentos aplicados às parcelas foram cinco, com as profundidades de semeadura de 0,$0 ; 2,0 ; 4,0 ; 6,0 \mathrm{e} 8,0 \mathrm{~cm}$ e, nas subparcelas, os métodos de superação da dormência com e sem escarificação. Cada parcela experimental foi constituída de 25 sementes. A partir do $10^{\circ}$ dia de semeadura iniciou-se a contagem de plantas emergidas, a fim de se determinar o índice de velocidade de emergência e, aos 35 dias posteriores à semeadura, avaliou-se a emergência das plântulas, a altura de plantas e a matéria seca da parte aérea. As sementes de $B$. dictioneura semeadas em torno de $4,0 \mathrm{~cm}$ de profundidade e submetidas à escarificação mecânica apresentaram melhor desenvolvimento em todos os parâmetros avaliados. A semeadura superficial e aquela em profundidades abaixo de $4,0 \mathrm{~cm}$ mostraram-se ineficientes para o desenvolvimento inicial de $B$. dictioneura.
\end{abstract}

Palavras-chave: desenvolvimento, escarificação, forrageira, germinação, pastagem.

\section{ABSTRACT}

\section{Sowing depth and breaking dormancy at early seed growth of Brachiaria dyctioneura (Fig. \& De Not.) Stapf (1919) cv. Llanero}

Brazil is the largest producer, consumer and exporter of forage seeds from tropical climate. The objective of this study was to evaluate the initial development of Brachiaria dictyoneura cv. Llaneroaccording to sowing depth and methods of breaking dormancy. The experiment was conducted in a greenhouse in a randomized block design with four replications in a split plot design. The five treatments used in the experiment were sowing depths $(0 ; 2.0$; $4.0 ; 6.0$ and $8.0 \mathrm{~cm}$ ) and methods of breaking dormancy (with and without scarification)in subplots. Each plot consisted of 25 seeds and from the $10^{\text {th }}$ day of sowing, emerged plants were counted to determine the emergence

\footnotetext{
Recebido para publicação em 18/03/2013 e aprovado em 04/02/2014.

Engenheiro-Agrônomo, Mestre. Universidade Federal de Lavras, Campus Universitário, 37200-000, Lavras, Minas Gerais, Brasil. alan_zuffo@ hotmail.com (autor para correspondência). 2 Engenheiro-Agrônomo, Mestre. Universidade Federal do Piauí, Campus Professora Cinobelina Elvas, Rodovia BR 135 Km 3, 64900-000, Bom Jesus, Piauí, Brasil. fabricioandradeagro@gmail.com

${ }_{3}^{3}$ Engenheiro-Agrônomo, Mestre. Universidade Federal do Piauí, Campus Professora Cinobelina Elvas, Rodovia BR 135 Km 3, 64900-000, Bom Jesus, Piauí, Brasil. luanaalves.agro@gmail.com

${ }^{4}$ Engenheiro-Agrônomo, Mestre. Universidade Federal do Piaú, Campus Professora Cinobelina Elvas, Rodovia BR 135 Km 3, 64900-000, Bom Jesus, Piauí, Brasil. kren.oliveira@hotmail.com

${ }^{5}$ Engenheiro-Agrônomo, Mestre. Universidade Federal do Piauí, Campus Professora Cinobelina Elvas, Rodovia BR 135 Km 3, 64900-000, Bom Jesus, Piauí, Brasil. robertofolha2010@hotmail.com

${ }^{6}$ Engenheiro-Agrônomo, Mestre. Universidade Federal do Piauí, Campus Professora Cinobelina Elvas, Rodovia BR 135 Km 3, 64900-000, Bom Jesus, Piauí, Brasil. acpiauilino@yahoo.com.br
} 
speed index and on the $35^{\text {th }}$ day after sowing, the seedlings emergence, plant height and the dry mass of shoots were evaluated. Seeds of B. dictioneura sown at $4.0 \mathrm{~cm}$ of deepness and submitted to mechanical scarification showed better growth in all parameters evaluated. The surface sowing and at depths below $4.0 \mathrm{~cm}$ are inefficient for establishing B. dictioneurapastures.

Keywords: development, forage, germination, scarification, pasture.

\section{INTRODUÇÃO}

O Brasil possui o segundo maior rebanho bovino do mundo, com cerca de 198 milhões de animais (USDA, 2012). As forrageiras de clima tropical, principalmente as gramíneas (Poaceae) perenes cultivadas, constituem importante fonte de proteínas para a alimentação animal, graças ao baixo custo e ao alto potencial de produção. Independentemente do sistema de produção, a dieta do rebanho de corte brasileiro, aproximadamente $99 \%$, é alicerçada nas pastagens (Castro et al., 2008).

As principais poáceas, cultivadas no Brasil (em termos de área plantada) são facilmente estabelecidas por via de sementes (Castro et al., 2008). Nesse cenário, o Brasil é o maior produtor, consumidor e exportador de sementes de espécies forrageiras de clima tropical, com uma produção de 70 mil toneladas na safra 2008/2009 (Abrasem, 2010). Segundo Costa et al. (2011), os cultivares do gênero Brachiaria representam mais de $80 \%$ da área.

A Brachiaria dictyoneura cv. Llanero, Poácea forrageira perene, originária da África Tropical, que tem nas sementes sua principal forma de propagação, apresenta tolerância a solos ácidos, de baixa fertilidade natural, e grande capacidade de adaptação a solos arenosos, graças a seu sistema radicular profundo (Costa et al., 2010).

Entretanto, a dormência pode interferir no uso das sementes forrageiras, por impedir a germinação e interferir diretamente no estabelecimento uniforme da pastagem (Almeida \& Silva, 2004; Costa et al., 2011). Entende-se como dormência o mecanismo pelo qual as sementes, mesmo viáveis e com todas as condições favoráveis (água, luz, temperatura), não germinam (Castro \& Vieira, 2001). A germinação das sementes é regulada pela interação das condições ambientais com seu estado de aptidão fisiológica, sendo que cada espécie de planta exige um conjunto de requerimentos ambientais necessários para a germinação de suas sementes, como: a disponibilidade de água, luz, temperatura e a profundidade de semeadura (Carvalho \& Christoffoleti, 2007).

A profundidade de semeadura da semente é um fator relevante para sua germinação (Oliveira \& Scivittaro, 2007), variando de acordo com as culturas. A semeadura ideal deve ser realizada a uma profundidade suficiente para facilitar a absorção de nutrientes e a sustentação da planta, promovendo uma germinação rápida e uniforme, com o mínimo gasto de reservas (Shanmuganathan \& Benjamin, 1992).

Na literatura, há trabalhos apontando para o efeito da profundidade de semeadura e dos métodos de superação de dormência no desenvolvimento inicial de plantas forrageiras. Trabalhando com Brachiaria brizantha, $B$. decumbens, B. ruziziensis e Panicum maximum cv. Tanzânia, em diferentes profundidades de semeadura, Pacheco et al., (2010) observaram redução na velocidade de emergência, decorrente do aumento da profundidade de deposição da semente. Esses autores concluíram que a profundidade de semeadura, até um centímetro, é adequada para essas espécies.

Objetivando identificar alternativas para a superação da dormência, Almeida \& Silva (2004) estudaram os efeitos fisiológicos de tratamentos térmico e químico $\left(\mathrm{H}_{2} \mathrm{SO}_{4}\right)$, em sementes de B. dictyoneura, e concluíram que ambos os métodos constituem alternativas para reduzir a dormência das sementes. Contudo, particularmente em relação ao calor, a deterioração pode ser acelerada durante o armazenamento. Sendo assim, o método químico apresenta melhores efeitos, graças ao período de longevidade da semente.

Apesar da sua eficiência, o tratamento químico poderá ocasionar danos aos trabalhadores envolvidos e à qualidade física da semente, além de contaminar o meio ambiente. Não há trabalhos na literatura com o objetivo de indicar a profundidade de semeadura que proporciona melhor germinação de $B$. dictyoneura. Estudos básicos sobre o desenvolvimento inicial da $B$. dictioneura, em diferentes profundidades de semeadura e diferentes métodos de superação de dormência fazem-se necessários.

Tendo em vista a escassez de material na literatura e a importância da forrageira como fonte de alimento para o rebanho bovino, são necessários novos estudos que visem às alternativas tecnológicas, aliando a eficiência operacional e a segurança ambiental.

Sendo assim, objetivou-se, com este estudo, avaliar o desenvolvimento inicial de Brachiaria dictyoneura cv. Llanero, em função da profundidade de semeadura e dos métodos de superação de dormência. 


\section{MATERIAL E MÉTODOS}

O experimento foi realizado em casa de vegetação, na área experimental do campus da Universidade Federal do Piauí (UFPI) em Bom Jesus-PI $\left(09^{\circ} 04^{\prime} 28^{\prime \prime} \mathrm{S}\right.$, $44^{\circ} 21^{\prime} 31^{\prime \prime} \mathrm{O}$, em altitude média de $277 \mathrm{~m}$ ), de agosto a setembro de 2012.

O clima da região é do tipo Aw, segundo a classificação global de Köppen, com duas estações bem definidas, sendo uma seca, de maio a setembro, e, outra, chuvosa, de outubro a abril. Durante a realização do estudo foram registradas, hora a hora e diariamente, a temperatura e umidade relativa do ar, sendo posteriormente calculadas as médias desses dados (Figura 1).

Foram utilizadas sementes de Brachiaria dictyoneura cv. Llanero, de um mesmo lote comercial, que foi dividido em duas porções. As sementes da primeira porção foram mantidas intactas (não escarificadas) tiveram suas análises realizadas, de acordo com Brasil (2009), e mostraram teor de pureza de $61 \%$, poder de germinativo de $80 \%$ e valor cultural de $48,8 \%$. A segunda porção de sementes foi submetida à escarificação manual, por atrito na palma da mão, para a retirada dos envoltórios externos (glumas e glumelas).

O delineamento experimental utilizado foi o de blocos casualizados, com quatro repetições, em esquema de parcela subdividida. Os tratamentos aplicados às parcelas foram as cinco profundidades de semeadura $(0,0$; 2,0; 4,0; 6,0 e 8,0 cm) e, nas subparcelas, os métodos de superação da dormência (com e sem escarificação).

Após o beneficiamento, foram semeadas, com uma pinça de mão, em bandejas plásticas perfuradas no fundo, em substrato composto de areia lavada e previamente esterilizada em autoclave. Cada bandeja constou de duas repetições de 25 sementes que, após a semeadura, permaneceram sobre uma bancada de alvenaria, em ambiente protegido e sob condições normais de temperatura, fotoperíodo e umidade relativa do ar.

Durante a realização do experimento, foram feitas irrigações diárias para reposição da água evapotranspirada e manutenção da capacidade de campo do substrato. A partir do $10^{\circ}$ dia de semeadura, iniciou-se a contagem de plantas emergidas, a fim de se determinar o índice de velocidade de emergência (IVE), segundo forma de cálculo estabelecida por Maguire (1962), que considera as contagens diárias das plântulas emergidas entre o $10^{\circ} \mathrm{e}$ o $35^{\circ}$ dias posteriores à instalação do estudo.

Determinou-se também a percentagem de emergência total de plântulas (EP) de Brachiaria aos 35 dias após a semeadura (DAS) e fez-se, na mesma data, a determinação da altura de plantas (AP), utilizando-se régua milimetrada, posicionada na base do colo até o ápice da folha mais nova. Posteriormente, realizou-se a coleta da parte aérea das plântulas (cortadas rente à superfície do solo), sendo submetidas à secagem em estufa de ventilação forçada, a $60^{\circ} \mathrm{C}$, até atingir massa constante, a fim de se determinar a matéria seca da parte aérea (MSPA).

A comparação entre as médias foi realizada pelo teste de Tukey, a 5\% de probabilidade, utilizando-se o programa estatístico Sisvar (Ferreira, 2008). Os dados quantitativos obtidos para o fator profundidade foram analisados por meio de regressão polinomial, sendo as equações ajustadas utilizando-se os parâmetros de correlação e determinação para as variáveis avaliadas, em função das profundidades de semeadura e dos métodos de superação de dormência, empregando-se o programa estatístico SigmaPlot.

\section{RESULTADO E DISCUSSÃO}

Na Tabela 1 é apresentada a análise da variância. Constata-se que todas as variáveis em estudo foram significativamente $(\mathrm{p}<0,01)$ influenciadas pelos fatores métodos de superação de dormência e profundidade de semeadura. Interação entre ambos os fatores não se verificou, sendo assim, procedeu-se um estudo isolado entre os fatores.

O uso da escarificação mecânica para a remoção dos envoltórios externos mostrou ser eficiente, resultando em maiores percentagens de germinação, índice de velocidade de emergência, altura das plantas e matéria seca da parte aérea, quando comparados com os da testemunha, dos quais diferiram estatisticamente para todas as variáveis analisadas (Tabela 2). Resultados semelhantes foram observados por Meschede et al. (2004), ao utilizarem a escarificação mecânica em sementes de Brachiaria brizantha cv. Marandu. Isso se deve ao fato de a escarificação mecânica promover a remoção das glumas e glumelas que protegem a cariopse e aumentarem, assim, as trocas gasosas que eliminam a dormência (Câmara \& Stacciarini-Seraphin, 2002).

Segundo Marcos Filho (2005), a dormência é um mecanismo resultante da estratégia evolutiva das espécies frente às variações ambientais. Dessa forma, na ausência de condições específicas do ambiente, há interferência de um ou mais mecanismos de bloqueio, impedindo a transcrição da mensagem genética para a ativação da sequência metabólica que culminará na germinação. Entretanto, para formação de forragens são necessárias tecnologias de manejo que visem a promover a germinação rápida e uniforme, impedindo, assim, o surgimento de plantas daninhas.

A máxima profundidade de semeadura estimada, em termos de velocidade de emergência das plântulas de Brachiaria, ocorreu a $4,03 \mathrm{~cm}$ de profundidade, sendo que o ponto máximo do índice de velocidade de emer- 
gência estimado é de 7,00. A semeadura superficial e a profundidade de semeadura de 6,0 a $8,0 \mathrm{~cm}$ reduziram drasticamente a velocidade de emergência (Figura 2). Resultados obtidos neste estudo corroboram os obtidos por Foloni et al. (2009ab), que, utilizando sementes de Brachiaria brizantha cv. MG-5 e Marandu, obtiveram menores velocidades de emergência do que as das depositadas superficialmente e em profundidades superiores a $5,0 \mathrm{~cm}$, respectivamente.
As profundidades influenciaram, significativamente, a percentagem de emergência de plantas aos 35 dias (Figura 3), a equação de regressão se ajustou ao modelo quadrático das curvas $(\mathrm{p}<0,01)$. A maior taxa diária de emergência plântulas de Brachiaria dictioneura cv. Llanero estimada neste estudo, de $54,46 \%$, pode ser obtida com a deposição das sementes a 3,89 $\mathrm{cm}$ de profundidade (Figura 3). As sementes depositadas a $8,0 \mathrm{~cm}$ apresentaram baixa taxa de

Tabela 1. Resumo da análise de variância referente à emergência de plântulas (EP), índice de velocidade de emergência (IVE) altura de plântulas (AP), matéria seca da parte aérea (MSPA) das plântulas de Brachiaria dictioneura cv. Llanero aos 35 dias após a semeadura de sementes submetidas aos tratamentos de superação de dormência em diferentes profundidades de semeadura

\begin{tabular}{|c|c|c|c|c|c|}
\hline \multirow{2}{*}{ Fontes de Variação } & \multirow{2}{*}{ GL } & \multicolumn{4}{|c|}{ Quadrados Médios } \\
\hline & & $\mathbf{E P}(\%)$ & IVE & $\mathbf{A P}(\mathbf{c m})$ & MSPA (mg) \\
\hline Dormência (D) & 1 & $1361,75^{* *}$ & $20,04 * *$ & $13,51 * *$ & $1541,73 * *$ \\
\hline Profundidade $(\mathrm{P})$ & 4 & $3156,62 * *$ & $51,95^{* *}$ & $241,14 * *$ & $1277,39 * *$ \\
\hline $\mathrm{D} \times \mathrm{P}$ & 4 & $11,30^{\mathrm{ns}}$ & $0,56^{\mathrm{ns}}$ & $0,06^{\mathrm{ns}}$ & $14,04^{\mathrm{ns}}$ \\
\hline Bloco & 3 & 4,64 & 0,82 & 0,18 & 16,51 \\
\hline Erro 1 & 12 & 32,11 & 2,09 & 0,16 & 26,10 \\
\hline Erro 2 & 15 & 26,65 & 1,43 & 0,24 & 23,80 \\
\hline Média Geral & & 34,16 & 4,42 & 7,09 & 25,40 \\
\hline CV $1(\%)$ & & 16,59 & 22,65 & 5,77 & 20,11 \\
\hline $\mathrm{CV} 2(\%)$ & & 15,11 & 17,09 & 6,96 & 19,20 \\
\hline
\end{tabular}

* Significativo a $1 \%$ de probabilidade pelo teste $\mathrm{F} .{ }^{\text {ns }}$ - não significativo

Tabela 2. Emergência de plântulas (EP), índice de velocidade de emergência (IVE) altura de plântulas (AP), matéria seca da parte aérea (MSPA) das plântulas de Brachiaria dictioneura cv. Llanero aos 35 dias após a semeadura de sementes submetidas aos tratamentos de superação de dormência

\begin{tabular}{lcccc}
\hline Tratamento & EP $(\%)$ & IVE & AP $(\mathbf{c m})$ & MSPA $(\mathbf{m g})$ \\
\hline Testemunha & $28,33 \mathrm{~b}$ & $3,72 \mathrm{~b}$ & $6,51 \mathrm{~b}$ & $19,20 \mathrm{~b}$ \\
Escarificado & $40,00 \mathrm{a}$ & $5,13 \mathrm{a}$ & $7,67 \mathrm{a}$ & $31,61 \mathrm{a}$ \\
\hline
\end{tabular}

Médias seguidas pelas mesmas letras minúsculas nas colunas, não diferem entre si pelo teste de Tukey, a 5\% de probabilidade.

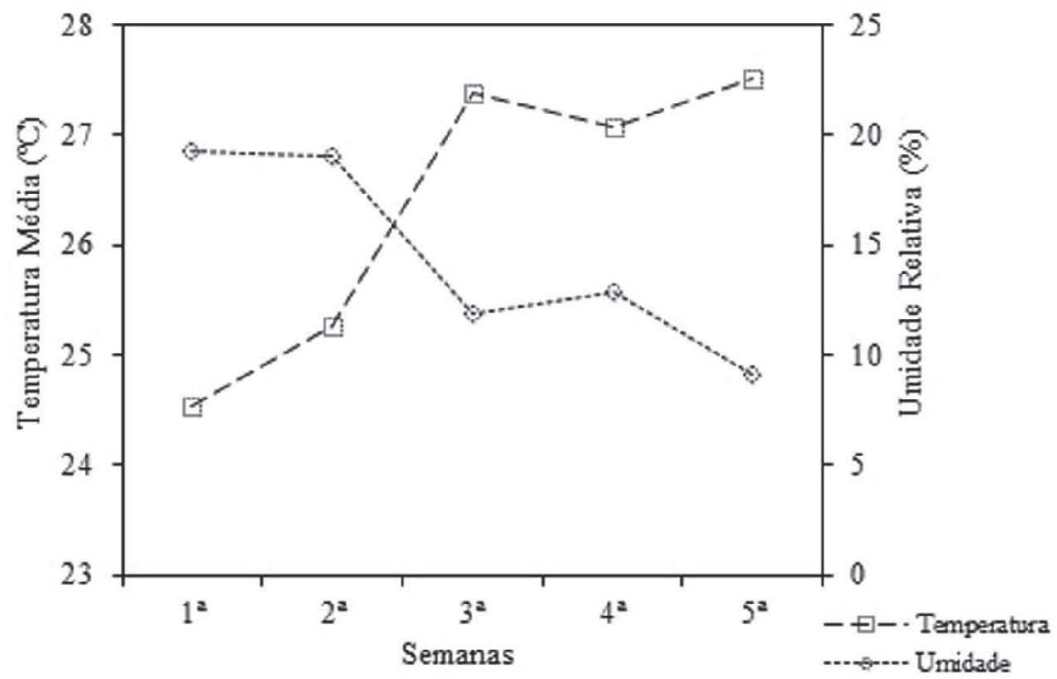

Figura 1. Temperatura média e umidade relativa do ar em Bom Jesus - PI, durante a condução do experimento (dados do INMET estação de Bom Jesus-PI). 
emergência, porém superior à daquelas depositadas na superfície do solo $(0 \mathrm{~cm})$.

Esses resultados corroboram, em parte, aos verificados por Foloni et al. (2009b) e Rezende et al. (2012), que mostraram que a profundidade de semeadura para espécies forrageiras encontra-se entre 2,5 e $5,0 \mathrm{~cm}$. Porém, a profundidade de semeadura a $2,5 \mathrm{~cm}$, para espécies do gênero Brachiaria mostrou-se a mais eficiente para a emergência de plantas. De acordo com Cazetta et al. (2005), Usberti \& Martins (2007) e Brancalion \& Marcos Filho (2008), espécies utilizadas para produção de palhada ou forragem necessitam apresentar altas taxas de crescimento inicial, para poderem competir com plantas daninhas e promoverem a rápida cobertura do solo.

A semeadura superficial mostrou-se ineficiente para emergência e velocidade de emergência das plantas (Fi- gura 2 e 3), pois, quando as sementes são depositadas entre 2,0 a 4,0 cm, dispõem de melhores condições, como presença de luz, umidade e temperatura. De acordo com Bewley \& Black (1994), a disponibilidade de água é extremamente importante para promover germinação, crescimento inicial de raízes e elongação de tecidos vegetais, e esses fatores são altamente influenciados pelo potencial matricial de água no solo, textura e área de contato entre solo e semente. Para a semeadura realizada em profundidades entre 6,0 e $8,0 \mathrm{~cm}$, há uma barreira mecânica sobre as sementes que mostrou ser mais limitante à emergência da Brachiaria e, consequentemente, ao índice de emergência.

A altura de plantas da $B$. dictyoneura foi significativamente influenciada pelas profundidades de semeadura (Figura 4). A equação ajustou de maneira quadrática, evidenciando o ponto máximo estimado da altura de 9,36

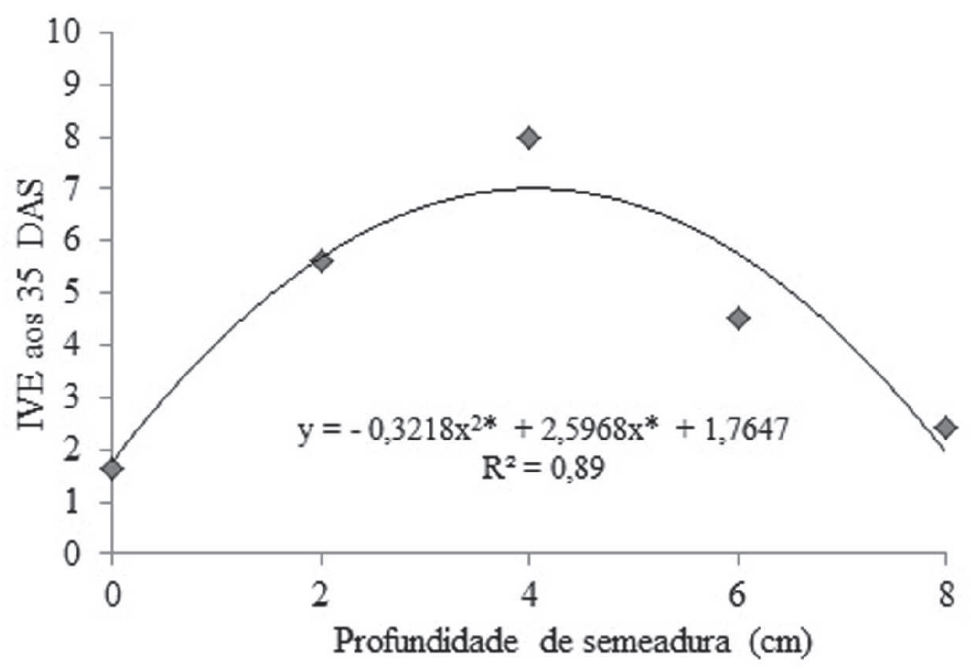

Figura 2. Índice de Velocidade de Emergência (IVE) de plantas de Brachiaria dictyoneura cv. Llanero, em função da profundidade. * significativo a $1 \%$ pelo teste "t" de Student.

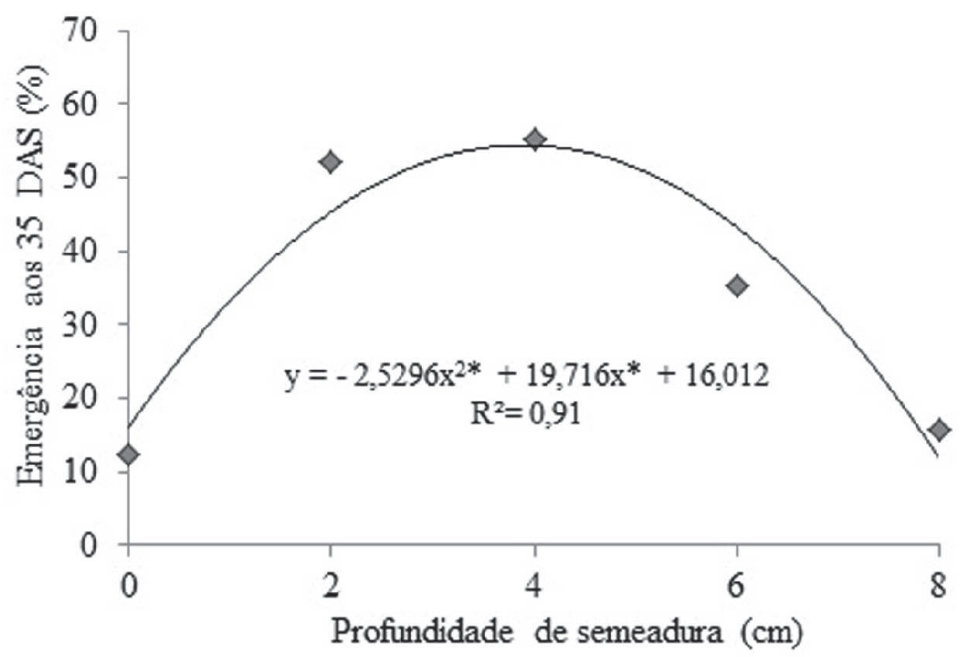

Figura 3. Percentagem de emergência de plantas de Brachiaria dictyoneura cv. Llanero aos 35 dias após semeadura (DAS), em função da profundidade de semeadura. * significativo a 1\% pelo teste " $t$ " de Student. 
$\mathrm{cm}$, quando as sementes foram depositadas na profundidade de $3,87 \mathrm{~cm}$, com a equação apresentando significância $(\mathrm{p}<0,01)$ para os tratamentos.

A altura de plantas é outro parâmetro essencial para se definir o potencial de competição da forrageira com as plantas daninhas. Observou-se que, quando depositadas na superfície e nas profundidades de 6,0 e 8,0 cm, há diminuição na altura de plantas. Pacheco et al. (2010), estudando profundidades de semeadura para a implantação de Brachiaria brizantha, B. decumbens, B. ruziziensis e Panicum maximum cv. Tanzânia, observaram que as semeaduras em superfície e a $8,0 \mathrm{~cm}$ prejudicaram as quatros espécies forrageiras, em relação às semeaduras realizadas nas profundidades de 1,0 e 4,0 $\mathrm{cm}$. Da mesma forma, Zimmer et al. (1994), trabalhando com as espécies $B$. brizantha e $B$. decumbens, relataram que a semeadura de forrageiras em profundidade inadequada provoca danos à distribuição espacial e à densidade populacional de plantas.

Profundidades excessivas aumentam a resistência mecânica, dificultando o processo de germinação e o crescimento da planta (Zimmer et al., 1994), além de reduzirem a temperatura, a disponibilidade de $\mathrm{O}_{2}$ e aumentarem o acúmulo de $\mathrm{CO}_{2}$ (Tillmann et al., 1994; Prado et al., 2002), formando compostos fermentados durante o processo respiratório (Taiz \& Zeiger, 2009) e afetando o processo germinativo.

$\mathrm{O}$ crescimento rápido das plantas de $B$. dictyoneura reduz a possibilidade de plantas daninhas transporem, pelo crescimento em altura, o dossel das plantas e interceptar quantidade significativa de luminosidade destinada ao seu crescimento. Dessa forma, semeaduras superficiais ou em camadas profundas podem resultar em baixa produção forrageira e, consequentemente, contribuir para o insucesso da atividade pecuária.
Na Figura 5, estão representados os resultados de acúmulo matéria seca da parte aérea de plântulas de $B$. dictyoneura, aos 35 dias após semeadura. De maneira geral, os resultados mais expressivos de produção de matéria seca ocorreram para a semeadura estimada na profundidade realizada a $3,92 \mathrm{~cm}$, com uma produção de matéria seca da parte aérea de 38,59 mg (Figura 5). Já aquelas depositadas superficialmente e nas profundidades de 6,0 e 8,0 cm não apresentaram boa capacidade de produção de matéria, o que corrobora com os estudos desenvolvidos por Foloni et al. (2009a) para sementes de $B$. brizantha cv. MG-5.

A produção de matéria seca é um dos principais fatores avaliados em espécies forrageiras e, segundo Garcia et al. (2004), altas produções são fundamentais para a introdução de bovinos na área para o pastejo. Sbrissia et al. (2003), trabalhando com a forrageira Tifton 85 (Cynodon spp.), relataram que, à medida que aumenta a altura dessa forrageira, aumenta também a produção de matéria seca, linearmente, corroborando os resultados obtidos neste estudo, em que a profundidade em torno de 4,00 $\mathrm{cm}$ apresentou maior altura de plantas (Figura 4) e, consequentemente, maior matéria seca da parte aérea, na mesma profundidade, em relação às outras profundidades, tratamentos que apresentaram menores valores para essa variável (Figura 5).

Por se tratar de uma gramínea, cujo metabolismo de fixação é $\mathrm{C}_{4}$, a $B$. dictioneura apresenta produção elevada. Provavelmente, por ser uma forrageira mais alta, maior será a quantidade e maior o tamanho das folhas, refletindo-se, assim, em mais fotossíntese e mais fotoassimilados, elevando a produção de matéria. As sementes de $B$. dictioneura depositadas cerca de $4,0 \mathrm{~cm}$ de profundidade apresentaram melhor desenvolvimen-

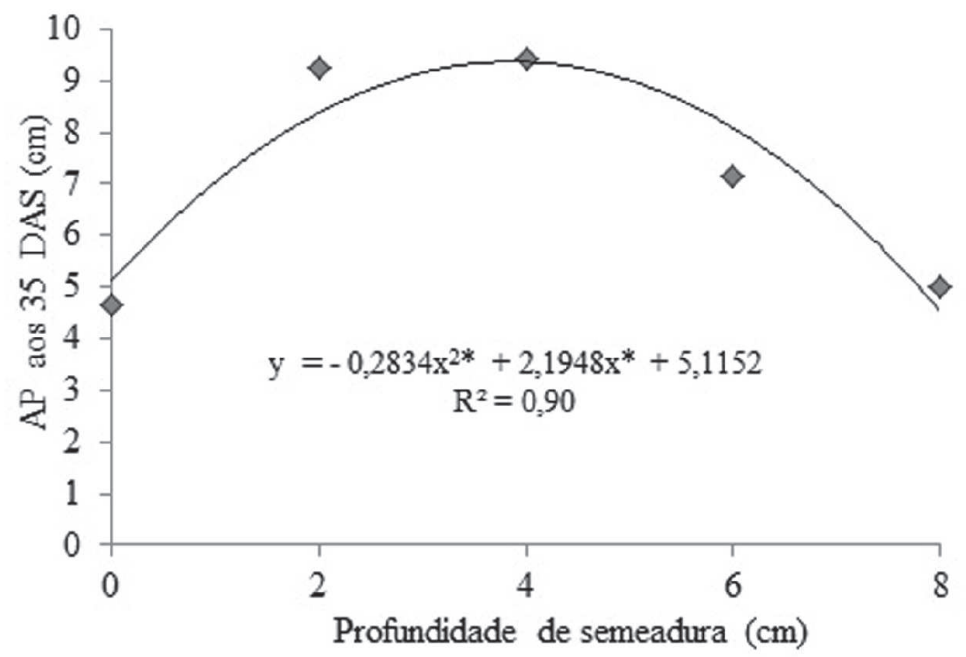

Figura 4. Altura de plantas (AP) de Brachiaria dictyoneura cv. Llanero aos 35 dias após a semeadura (DAS), em função da profundidade de semeadura. * significativo a 1\% pelo teste "t" de Student. 


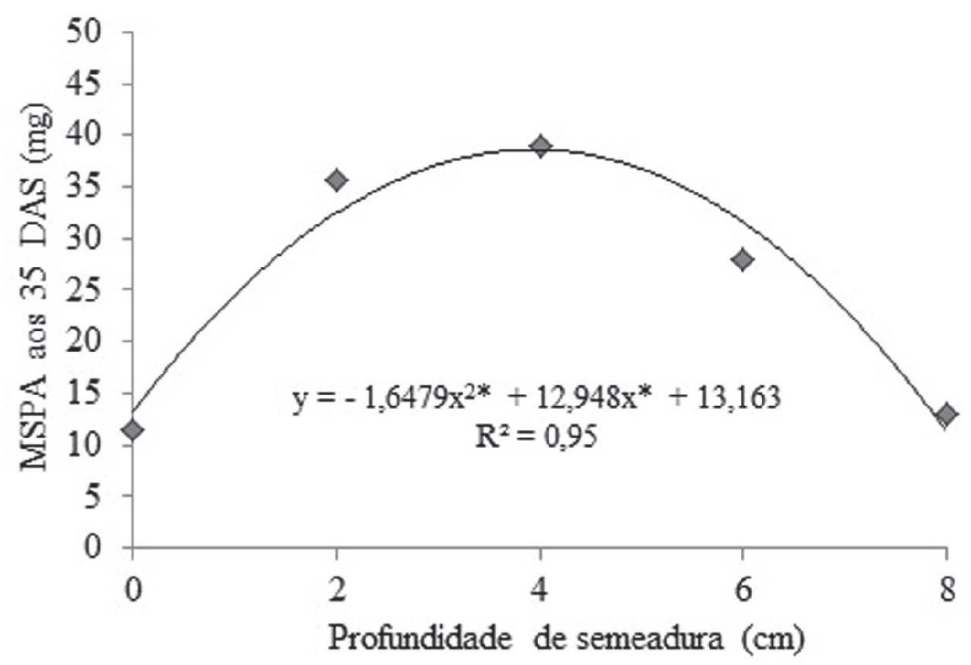

Figura 5. Matéria seca aérea de plantas (MSAP) de Brachiaria dictyoneura cv. Llanero aos 35 dias após a semeadura (DAS), em função da profundidade de semeadura. * significativo a $1 \%$ pelo teste "t" de Student.

to, possivelmente graças às melhores condições edafoclimáticas encontradas nessa profundidade.

Fica claramente evidenciado que a dormência da semente e a profundidade afetam o crescimento e o desenvolvimento inicial dessa forrageira. Os pecuaristas devem ficar atentos a essas variáveis, a fim de obterem o máximo desempenho fisiológico da semente, objetivando promover uma germinação com população uniforme e adequada. Apesar de ser uma semente pequena, a $B$. dictioneura apresenta características intrínsecas e de adaptação que permitem germinar vigorosamente na profundidade em torno de $4,0 \mathrm{~cm}$.

\section{CONCLUSÕES}

$\mathrm{O}$ uso da escarificação constitui alternativa para a redução da dormência nas sementes de $B$. dictioneura.

A melhor profundidade de semeadura é de cerca de 4,0 cm, por promover melhores percentagens de germinação, índice de velocidade de emergência, altura de plantas e matéria seca.

\section{AGRADECIMENTOS}

Os autores expressam seus agradecimentos à CAPES (Coordenação de Aperfeiçoamento de Pessoal de Nível Superior) e ao CNPq (Conselho Nacional de Desenvolvimento Científico e Tecnológico), pela concessão de bolsas, e à Universidade Federal do Piauí (UFPI), pelo apoio logístico.

\section{REFERÊNCIAS}

Almeida CR \& Silva WR (2004) Comportamento da dormência em sementes de Brachiaria dictyoneura cv. Llanero Submetidas às ações do calor e do ácido sulfúrico. Revista Brasileira de Sementes, 26:44-49.
Abrasem (2010) Anuário Abrasem. Disponível em: <http:// www.abrasem.com.br/>. Acessado em: 17 de Outubro de 2012.

Bewley JD \& Black M (1994) Seeds: physiology of development and germination. 2nd ed. Plenum Press, New York. 445p.

Brasil, Ministério da Agricultura e Reforma Agrária (2009) Regras para análise de sementes. Brasília, Secretaria Nacional de Defesa Agropecuária. 398p

Brancalion PHS \& Marcos Filho J (2008) Distribuição da germinação no tempo: causas e importância para a sobrevivência das plantas em ambientes naturais. Informativo Abrates, 18:11-17.

Câmara HHLL \& Stacciarini-Seraphin E (2002) Germinação de sementes de Brachiaria brizantha cv. Marandu sob diferentes períodos de armazenamento e tratamento hormonal. Pesquisa Agropecuária Tropical, 32:21-28.

Carvalho SJP \& Christoffoleti PJ (2007) Influência da luz e da temperatura na germinação de cinco espécies de plantas daninhas do gênero Amaranthus. Bragantia, 66:527-533.

Castro PRC \& Vieira EL (2001) Aplicações de reguladores vegetais na agricultura tropical. Guaíba, Agropecuária. 132p.

Castro PRC, Klyge RA \& Sestari I (2008) Manual de fisiologia vegetal: Fisiologia de cultivos. Piracicaba, Editora Agronômica Ceres. 864p.

Costa NL, Townsend CR, Magalhães JA \& Pereira RGA (2010) Manejo de pastagens de Brachiaria dictioneura na Amazônia Ocidental. Infoteca-e. Disponível em: <http://www.infoteca.cnptia.embrapa.br/ bitstream/doc/883159/1/ClicNews201011.pdf >. Acessado em: 15 de Outubro de 2012.

Costa CJ, Araújo RB \& Bôas HDCV (2011) Tratamentos para a superação de dormência em sementes de Brachiaria humidicola (Rendle) Schweick. Pesquisa Agropecuária Tropical, 41:519-524.

Cazetta DA, Fornasieri Filho D \& Girotto F (2005) Composição, produção de matéria seca e cobertura do solo em cultivo exclusivo e consorciado de milheto e crotalária. Acta Scientiarum Agronomy, 27:575580.

Ferreira DF (2008) SISVAR: um programa para análises e ensino de estatística. Revista Symposium, 6:36-41.

Foloni JSS, Custódio CC, Pompei FP \& Vivan MR (2009a) Instalação de espécie forrageira em razão da profundidade no solo e contato com fertilizante formulado NPK. Pesquisa Agropecuária Tropical, 39:712 .

Rev. Ceres, Viçosa, v. 61, n.6, p. 948-955, nov/dez, 2014 
Foloni JSS, Custódio CC, Caldeira FJ \& Calvo CL (2009b) Emergência de plântulas de Brachiaria brizantha influenciada por escarificação das sementes, uso de adubo e profundidade de semeadura. Científica, 37:89-97.

Garcia R, Rocha FC, Bernaldino RS \& Gobbi KF (2004) Forrageiras utilizadas no sistema agricultura pecuária. In: Zambolim L, Silva AA \& Agnes HL (Eds.) Manejo integração: integração agricultura-pecuária. Viçosa, UFV. p.331-351.

Maguire JD (1962) Speed of germination: aid in selection and evaluation for seedling emergence and vigor. Crop Science, 2:176-177.

Marcos Filho J (2005) Fisiologia de sementes de plantas cultivadas. Piracicaba, FEALQ. 465p.

Meschede DK, Sales JGC, Braccini AL, Scapim CA \& Schuab SRP(2004) Tratamento para superação de dormência das sementes de capimbraquiária cultivar Marandú. Revista Brasileira de Sementes, 26:7681

Oliveira RP \& WB Scivittaro (2007) Tegumento e profundidade de semeadura na emergência de plântulas e no desenvolvimento do porta-enxerto Trifoliata. Revista Brasileira de Sementes, 29:229-235

Pacheco LP, Pires FR, Monteiro FP, Procópio SO, Assis RL \& Petter FA (2010) Profundidade de semeadura e crescimento inicial de espécies forrageiras utilizadas para cobertura do solo. Ciência e Agrotecnologia, 34:1211-1218.

Prado RM, Coan O \& Villar MLP (2002) Compressão do Solo e Profundidade de Semeadura na Emergência e no Crescimento Inicial da Cultura do Milho (Zea mays L.). Revista Científica Eletrônica de Agronomia, 2:1-6.
Rezende AV, Andrade LP, Almeida GBS, Rabelo HS, Rabelo FHS, Landgraf PRC, Nogueira DA \& Vilela HH (2012) Efeito da profundidade e da mistura de sementes ao adubo químico na emergência de plântulas de espécies forrageira. Revista Agrarian, 5:115-122.

Sbrissia AF, Silva SC, Matthew C, Carvalho CAB, Carnevalli RA, Pinto LFM, Fagundes JL \& Pedreira CGS (2003) Tiller size/density compensation in grazed Tifton 85 bermudagrass swards. Pesquisa Agropecuária Brasileira, 38:1459-1468.

Shanmuganathan V \& Benjamin LR (1992) The influence of sowing depth and seed size on seedling emergence time and relative growth rate in spring cabbage (Brassica oleracea var. capitata L.). Annals of Botany, 69:273-276.

Taiz L \& Zeiger E (2009) Fisiologia vegetal. 4 ed. Porto Alegre, Artmed. 719p.

Tillmann MAA, Piana Z, Cavariani C \& Minami K (1994) Efeito da profundidade de semeadura na emergência de plântulas de tomate (Lycopersicon esculentum Mill.). Scientia Agricola, 51:260-263.

USDA (2012) Relatórios da Agência. Disponível em: <http:// www.usda.gov>. Acessado em: 20 de Outubro de 2012.

Usberti R \& Martins L (2007) Sulphuric acid scarification effects on Brachiaria brizantha, B. humidicola and Panicum maximum seed dormancy release. Revista Brasileira de Sementes, 29:143-147.

Zimmer AH, Macedo MCM, Barcellos AO \& Kichel AN (1994) Estabelecimento e recuperação de pastagens de Brachiaria. In: Manejo da pastagem. Peixoto AM, Moura JC \& Faria VP (Eds.) Piracicaba, FEALQ.p.153-208. 